\title{
A Descriptive Study to Assess the Knowledge on Infection Control among Staff Nurses in I.C.U in Selected Hospitals in Chennai
}

\author{
V. Hemavathy ${ }^{1}$, Girija Bhaskaran ${ }^{2}$, Y. Sudha ${ }^{3}$ \\ 1Principal and Professor, Department of Mental Health Nursing, SreeBalaji College of Nursing, Bharath University Tamil Nadu, India \\ ${ }^{2}$ Professor, HOD Dept of Medical and Surgical Nursing, SreeBalaji College of Nursing, Bharath University Tamil Nadu, India \\ ${ }^{3}$ M.Sc. Nursing, Dept of Medical and Surgical Nursing, SreeBalaji College of Nursing, Bharath University Tamil Nadu, India
}

\begin{abstract}
The aim and objective of the study was to knowledge on infection control among staff nurses in I.C.U in selected Hospitals Chennai, India. A descriptive study was adopted. A total of 30 nurses participated in the present study, randomly chosen from I.C.U. An observational checklist was used for data collection after getting their informed consent. Self-made scoring system was used to categorize the participants as whether they follow the correct practice, partially correct practice or the incorrect practice. Purposive sampling technique was adopted to select the sample of the study. The result of the study concluded that the frequency and percentage distribution of level practice on infection control among staff nurses reveals that 24(80\%) staff nurses were found following correct practices, $4(13.3 \%)$ of staff nurses were found following partially correct practices, and 2(6.7\%) were following incorrect practices. The study reveals that some nurses were correctly practicing the various aspects of infection controlbut for some who were not found to be completely responsible for infection control in the hospital; their problems were sort out such as inadequate staff in the I.C.U; less supervision, increase workloads, etc. It is the responsibility of the nurse to care for the environment and public health particularly in relation to the infection control. The importance of training regarding infection control cannot be overemphasized; lack of proper and complete knowledge about infection control impacts practices of appropriate waste disposal among staff nurses in the hospital.
\end{abstract}

Keywords: Nurse, infection Control, infection control management, I.C.U, hospital

\section{Introduction}

Microbes are everywhere in the biosphere and their presence in variably affects the environment they are growing in. The effects of microbes on their habitats can he beneficial or harmful or in apparent with regards to human affairs. The beneficial effects of microbes drive from their metabolic activities in the environment, theirassociations with plants and animals and their use in food production and biotechnological processes. The primary harmful effect of microbes upon our existence and civilization is that they are an important cause of disease in animals and human beings, and they are agents of spoilage and decomposition of our foods, textiles and dwellings. A microbe, which is capable of causing infectious disease in human being, is called a pathogen. Four groups of microbes contain pathogens: Bacteria, Fungai, Protozoa and Viruses. Pathogens are the cause of infectious disease (Madison, 2006).

Infection is the invasion of the body by pathogenic microorganism that invades the issue and overcome the patient's resistance and multiplies. In healthcare settings the patients Ay be infected by their own organism called as endogenous infection or may be by organism from other people called as exogenous infection. Cross infection organism are Went and are resistant to several antibiotics especially in health care facilities like surgical wards, intensive care units (Ananthanarayan, 2002).

Nosocomial infections are defined as an infection acquired during or as a result of hospitalizations. The patients neither have these infections not are incubating these infection on admission. Generally a patient who develops an infection after 48 hours of hospital admission is considered to have a nosocomial infection. Some nosocomial infection may not as disease immediately and can manifest event after discharge (Abraham, 2003).

Infection is common but often avoidable complication of health care which has major the patient and the health care service. It has been estimated that up to one third of (Attired infection could be prevented by improved infection control practice. (Haley 1985)

Infection occurs in hospitals and health post because patients who visit these facilities have often many different illness; while in the hospital or health post they may transmit there organisms through direct or indirect contact. Factors which make a person more likely to get infect are of certain ages (newborn's, elderly) underlying diseases (diabetes, malnourishment). Drug therapy (antibiotics, steroids) and invasive procedures (surgery and catheterization) (Ayllife, 1992).

Two modes of contact transmission exist, direct and indirect contact transmission. Direct contact transmission consist of direct body surface to body surface contact and physical transfer of bacteria between a susceptible host and an infected or colonized individual, for example bathing or turning a patient. Indirect contact transmission involves contact of a susceptible host with contaminated objects like medical instruments, dressings, used gloves 


\section{International Journal of Science and Research (IJSR) \\ ISSN (Online): 2319-7064}

Index Copernicus Value (2013): 6.14 | Impact Factor (2014): 5.611

that are not changed between patient's care and unwashed hands (Kelly, 2002)

In an intensive care unit, people are crowded and health care workers are frantically running from patient to patient. Have washing might not be adhered to assiduously enough. Health care working going from a wound site to an intravenous catheter without washing their hands can trigger infection among many patients (Wenzel, 1999).

Nosocomial infections contributes greatly to morbidity, mortality and often length of stay in the intensive care unit (ICU) with enormous additional costs by patients and their families. Multi-drug resistance is the another notorious character of these organisms (John 1999).

\section{Material and Method}

A descriptive study was conducted to assess the knowledge on infection control among staff nurses in I.C.U. The study was conducted in selected Hospitals. Study participants included staff nurses working in the I.C.U. A total of 30 staff nurses participated in the study and were observed for infection control practices. An observational checklist was predesigned to observe the practice of the staff nurses in I.C.U. There were 25 dichotomous questioned prepared in the observational checklist. The data was collectedby observing the practices of infection control and each correct practices was given a score of 'one' and wrong practices was given a score of 'zero'. Self-made scoring system was used to categorize the participants as whether they follow the correct practice, partially correct practice or the incorrect practice.

The score was interpreted as follows:

\begin{tabular}{|c|c|}
\hline Level of Practice & Score of Percentage \\
\hline Correct practices & $>75 \%$ \\
\hline Partially correct practices & $51-75 \%$ \\
\hline Incorrect practices & $<50 \%$ \\
\hline
\end{tabular}

\section{Results}

The findings of the study are discussed in terms of objective and hypothesis of the study.

\section{Sample characteristics:}

- Most of the subjects (90\%) were in the age group of 21-30 years and minimum numbers of subjects $(10 \%)$ were found in the age group of 40 years and above.

- Most of the subjects were female $93.3 \%$ and male $6.7 \%$.

- With regard to professional qualification most of the subjects were GNM (40\%), B.Sc(N) with (53.3\%) and the minimum subjects was an post Bsc $(\mathrm{N})$ covering only $(6.7 \%)$ and the minimum subjects was M.Sc(N) $(0 \%)$.

- Most of the subjects (20\%) had 5-6 years, (3.3\%) and above 6 years experiences, (33.3\%) had $1.1-2$ years experience, and minimum (36.7\%) had $3-4$ years experience and $<1$ year experience.

- Most of the subjects (33.3\%) got information from the colleagues which may be due to comfort approach,
(16.7\%) got information fromthe supervisors, (30\%) got information from the doctors, and (20\%) mass media which may be due to easy accessibility.

The objective was to assess the knowledge on infection control among staff nurses in I.C.U. The frequency and percentage distribution of level of practice on infection control among staff nurses reveals that $24(80 \%)$ had were following correct practices, $4(13.3 \%)$ of staff nurses were following partially correct practices, and $2(6.7 \%)$ were following incorrect practices.

Table 1: Level of practices on infection control among staff nurses in I.C.U

\begin{tabular}{|c|c|c|}
\hline Level of practice\% & No $(n=30)$ & Percentage $\%$ \\
\hline Correct practices & 24 & $80 \%$ \\
\hline Partially correct practices & 4 & $13.3 \%$ \\
\hline Incorrect practices & 2 & $6.7 \%$ \\
\hline
\end{tabular}

Table 1 shows that $24(80 \%)$ of staff nurses were found following the correct practices, $4(13.3 \%)$ were found following partially correct practices and $2(6.7 \%)$ were found to be following the incorrect practices of infection control in I.C.U.

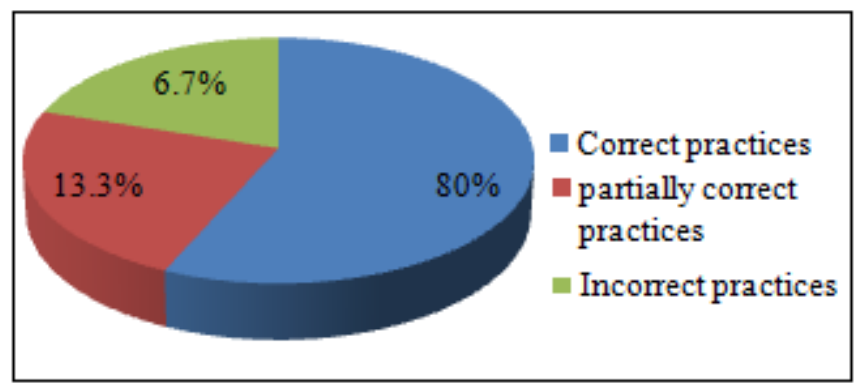

Figure 1: Percentage distribution on level of practices on infection control among staff nurses in I.C.U.

\section{Discussion and Conclusion}

The participants involved in this study were assessed for the practice with regards to infection control. The study showed that only $80 \%$ of the staff nurses were found to be following the correct practices on infection control. The rest were ignorant on all counts regarding the practice. The implication drawn from the study are of vital concern to all health care team members and need to be incorporated in both theory and practice. The importance of training regarding infection control management cannot be overemphasized; lack of proper and complete knowledge about infection control impacts practices of appropriate waste disposal. Factors such as increase workload, lack of staff in the I.C.U, less supervision also have a major impact on the practice of infection control. Thus the following recommendation needs to be implemented: (i) strict implementation of hand washing techniques rules is the need of the hour, supervision of hand washing programme in the hospital and its documentation, (ii) conducting the orientation programme for the new staff members and (iii) organizing continuous awareness programme amongst the staff members. 


\section{International Journal of Science and Research (IJSR) \\ ISSN (Online): 2319-7064}

Index Copernicus Value (2013): 6.14 | Impact Factor (2014): 5.611

\section{References}

\section{Book References}

[1] Ananthanrayan, R \&Paniker, C.K. (2002). Text Book of Microbiology. (6ffied.).Chennai: Orient Longman.

[2] Aylliffe, G.A. \&Lowbury, E.J.(1992) Control gl Hospital infection: A practicalHand book, (31.ded,). Philadelphia: Chapman and hall medical.

[3] Bannet.,J.(1995),Hospital ed.).Philadelphia: raven Publications.

[4] Barbara, M.S. (1995). Infection and Nursing Practice.(1St ed.).Philadelphia: Mosby puplications.

[5] Basanvathappa, B.T (1998). Nursing Research. (red.). New delhi: Jaybee BrothersMedical puplications.

[6] Black, J.M, \&jacobs, E.M. (1997). Medical-Surgical Nursing: Clinical Management for Continuity of Care, (5 t.) Philadelphia:W.B. Saunders Company.

[7] Breathnach., A., (2005). Clinical Symposia On nosocomial infection.( ${ }^{\text {ST }}$ ed.).Mumbai: CMP MedicaPvt, ltd.

[8] Burns, N, \& Grove, S.K. (2001). The Practice of Nursing research: Conduct,Critique and Utilization. (4th ed.).Philadelphia: W.S.Saunders Company.

[9] Chalky, A.M. (1991). Hospital Acquired Infection Prinviple and Prevention.( $2^{\text {nd }}$ ed.). Great Britain: Butterworth Heinemman Ltd.

[10]Collins,B.J, (1991), Hospital Acquired Infection Principle and prevention.(2nded.).Great Britain: Butterworth Heinemman Ltd.

[11] Elizabeth, A.J, \&jennie, W, (2006). Infection Control in Clinical Practice.Edinburgh: Elsevier.

[12] Francis, C.M, \& Mario, S. (2000). Hospital Administration. ( $3^{\text {rd }}$ ed). New Delhi:Jaybee Brothers.

\section{Journal References}

[13] Adams, D.,et.al.(1992). A clinical evaluation of glove washing and re-used in dental practice. Journal of Hospital Infection. 20:153-62.

[14] Akash. D.,et. Al. (2005). Clinical and Microbiological Profile of Nosocomial Infection in the Pediatric Intensive care Unit. Journal of Indian paediatrics. 41:1238-1245.

[15] Atukorala, S.D. (1998). Monitoring effectiveness of controlling hospital acquired infection by prevalence Survey. Journal of Hospital infection.7(1):127129.Ayliffe G., et. Al. (1978). A test for hygienic hand disinfection. Journal of Hospital Infection. 11: 226-43.

[16] Barry, (1999). Hand washing a modest measure with big effects. British Medical Journal. 318:687-690.

\section{Online Journals}

[17] Badley, A. (1992). Infections rates of control venous pressure catheters: Comparison between newly placed catheters and those that have been changed. Retrieved from hftp://www.pubmetcom.

[18] Caroline, W., (2006). Hospital acquired infection rates less than 10 years ago. Retrieved from http://www.nursingtimes.

[19]Daleen, A., (2006). Implementing best practice strategies to prevent infection in the I.C.U. Retrived from: http://www.sciencedirect coin
[20] Dhawan, B., et. al. (2001). Infective complications of central venous catheters in 'cardiac surgical patients. Available online at: http://www.pubmed.com

\section{Unpublished Thesis}

1. Alex. A. (2003). A Comparative study on knowledge Level of Student Nurses \& Staff Nurses. Regarding Nosocomial Infection in a selected Hospital in Mangalore. Unpublished M.Sc. Nursing Dissertation, Rajiv Gandhi University, Bangalore.

2. John. J. (2006). Effectiveness of self Instructional Module on Aseptic Wound dressing Practices among Staff Nurse in Selected Hospital at Mangalore. Unpublished M.Sc. Nursing Dissertation, Rajiv Gandhi University, Bangalore.

\section{Net Reference}

[21] http://www.medicinet.com

[22] http://www.cdc.gov/infectioncontrol

[23] http://www.uptodate.com/home/content/topic.do

[24] http://allafrica.com/stories

[25]www.Wikipedia.com 